\title{
Risk of de novo aneurysm formation in patients with a prior diagnosis of ruptured or unruptured aneurysm: systematic review and meta-analysis
}

\author{
Enrico Giordan, MD, ${ }^{1}$ Giuseppe Lanzino, MD, ${ }^{1}$ Leonardo Rangel-Castilla, MD, ${ }^{1}$ \\ Mohammad Hassan Murad, MD, ${ }^{2}$ and Waleed Brinjikji, MD ${ }^{3}$ \\ 'Department of Neurologic Surgery, ${ }^{2}$ Evidence-Based Practice Center, and ${ }^{3}$ Department of Radiology, Mayo Clinic, Rochester,
Minnesota
}

\begin{abstract}
OBJECTIVE De novo aneurysms are rare entities periodically discovered during follow-up imaging. Little is known regarding the frequency with which these lesions form or the time course. This systematic review and meta-analysis was undertaken to estimate the incidence of de novo aneurysms and to determine risk factors for aneurysm formation.
\end{abstract}

METHODS The authors searched multiple databases for studies of patients with unruptured and ruptured aneurysms describing the rate of de novo aneurysm formation. The primary outcome was incidence of de novo aneurysm formation. A meta-analysis was performed using a random-effects model. The authors examined the associations of multiple aneurysms, prior subarachnoid hemorrhage, smoking, sex, age at presentation, and hypertension with de novo aneurysm formation.

RESULTS The meta-analysis included 14,968 aneurysm patients who received imaging follow-up from 35 studies. The overall incidence of de novo aneurysm formation was $2 \%(95 \% \mathrm{Cl} 2 \%-3 \%)$ over a mean follow-up time of 8.3 years. The estimated incidence density was $0.3 \%$ /patient-year. There was no statistically significant difference in rates of de novo aneurysm formation between patients who had ruptured aneurysms and those with unruptured aneurysms. In 8 studies, $11.2 \%$ of de novo aneurysms were found in patients with $\leq 5$ years of follow-up and $88.8 \%$ were found at $>5$ years. The mean time to rupture for de novo aneurysms was 10 years.

CONCLUSIONS This systematic review demonstrates that formation of de novo aneurysms is rare. Overall, routine screening for de novo aneurysms is likely to be of low yield and could be performed at time intervals of at least 5 to 10 years.

https://thejns.org/doi/abs/10.3171/2018.1.JNS172450

KEYWORDS de novo aneurysms; unruptured aneurysms; de novo formation; new aneurysms; ruptured aneurysms; de novo aneurysm incidence; risk factors; vascular disorders

$\mathrm{D}$ E novo aneurysm refers to a new aneurysm identified on imaging studies obtained after a study that demonstrated no aneurysm in that location. De novo aneurysms are usually discovered during follow-up imaging in otherwise asymptomatic intracranial aneurysm patients. There is little information about the need, frequency, and yield of scheduled imaging follow-up studies after successful treatment of ruptured or unruptured intracranial aneurysms to rule out possible de novo aneurysm formation. Due to the relatively small number of endpoints, most of the studies available on the subject do not allow for a clarification of the risks factors for de novo aneurysm formation nor can they make any definitive statements regarding the timing of aneurysm formation. In this systematic review and meta-analysis, we calculated the overall prevalence and cumulative incidence of de novo aneurysms in a population of patients with a prior diagnosis of brain aneurysm. We also sought to determine what risk factors, if any, were associated with development of de novo aneurysms and studied the timing of de novo aneurysm formation.

\section{Methods}

\section{Study Selection}

A comprehensive search of several databases from 


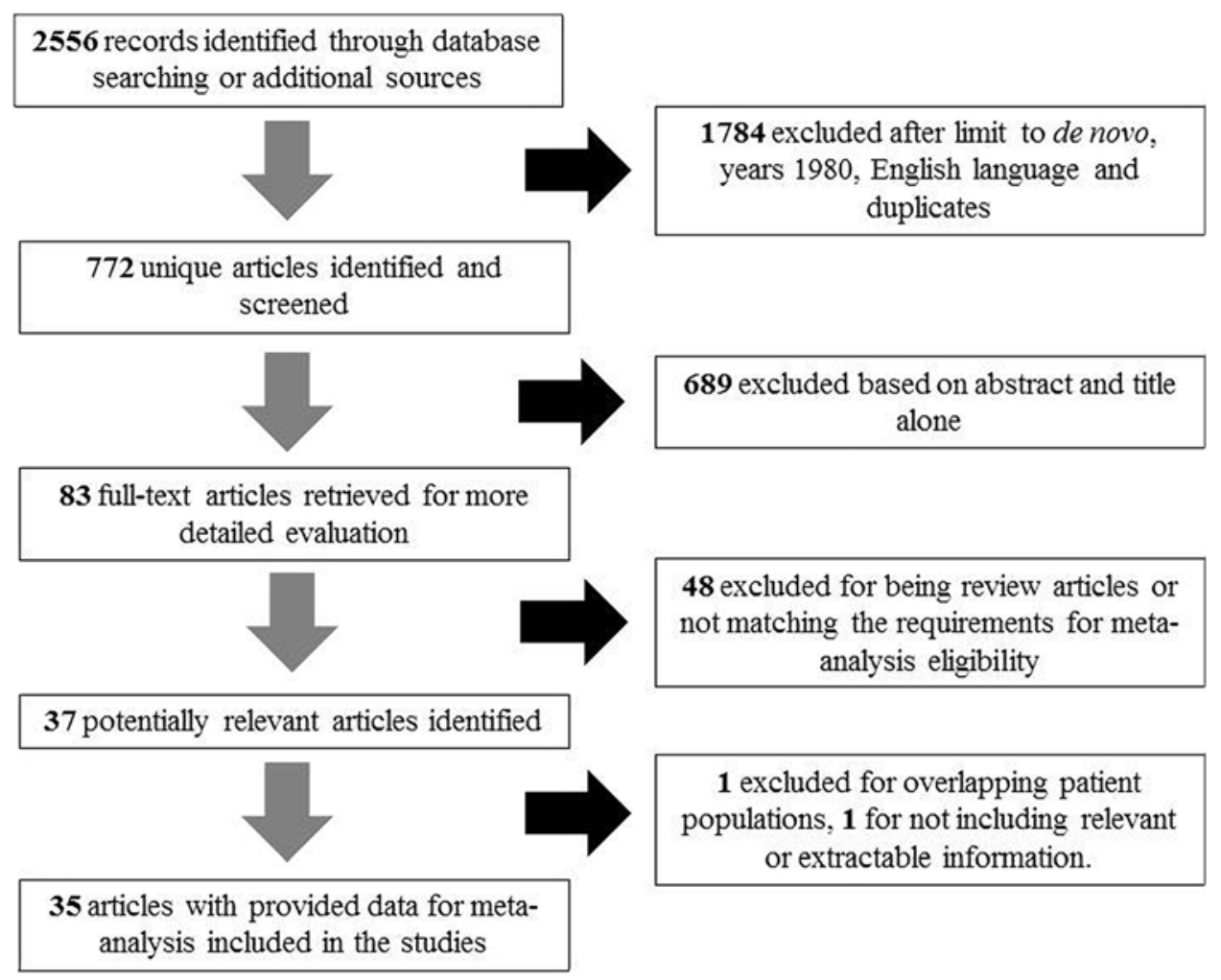

FIG. 1. Flow diagram summarizing the process of study selection.

1980 to June 2017 was designed and conducted by an expert medical reference librarian. The search terms were "intracranial aneurysm," "unruptured aneurysm," "aneurysm," "cerebral aneurysm," "de novo aneurysms," "new aneurysm," and "aneurysm formation," used alone and in combination. Databases included were PubMed, Epub Ahead of Print, Ovid MEDLINE In-Process \& Other Non-Indexed Citations, Ovid MEDLINE, Ovid EMBASE, Ovid Cochrane Central Register of Controlled Trials, Ovid Cochrane Database of Systematic Reviews, and Scopus. Controlled vocabulary supplemented with the keywords was used to search for de novo aneurysm formation in patients with a prior diagnosis of ruptured or unruptured aneurysms.

Inclusion criteria were the following: 1) studies describing "de novo" aneurysm formation in both longitudinal and retrospective series; 2) series with a mean or median imaging follow-up > 1 year; 3) studies published in English; 4) consecutive series of patients with both treated and untreated, unruptured or ruptured aneurysms; and 5) follow-up with MR angiography (MRA), digital subtraction angiography (DSA), or CT angiography (CTA). Studies with $<40$ patients, published in a language other than English, or with $<1$ year of follow-up were excluded. The type of treatment for ruptured and unruptured aneurysms was not taken into account, because it was not considered a significant factor affecting the rate of formation of "de novo" aneurysms. Two reviewers selected the included studies.

\section{Data Abstraction}

For each study, we extracted the following informa- tion: incidence of de novo aneurysms, patient age, patient sex, prior aneurysm subarachnoid hemorrhage (SAH), and follow-up time in patient-years. In addition, when possible, we analyzed and extracted separately the subpopulations of patients with ruptured and unruptured aneurysms, calculating the number of de novo events for each population and the mean interval between imaging at presentation and de novo aneurysm recognition. We defined a "de novo" aneurysm as an aneurysm that developed from a vessel that had been normal on previous imaging studies. When possible, we also defined the subpopulation of de novo aneurysms that were ruptured at diagnosis and the interval between de novo aneurysm diagnosis and rupture. Other risk factors studied included hypertension, smoking, sex, mean age at presentation, family history of intracranial aneurysm, and aneurysm multiplicity.

\section{Study Evaluation}

From each study we evaluated study design, study population, and imaging used in follow-up. We also evaluated risk of bias. To assess the risk of bias we modified the New Castle-Ottawa Quality Assessment Scale. The risk of bias was assessed based on the following questions: Did the study include all patients or consecutive patients with adequate radiological follow-up (MRA, CTA, or DSA)? Was follow-up length enough to ascertain the de novo formation (> 3 years)? Was definition of "de novo" aneurysm adequate? Studies judged to be at low risk of bias were defined as those with a predefined study protocol, adequate imaging follow-up (both MRA and DSA), and adequate 
TABLE 1. Summary of the characteristics of the included studies

\begin{tabular}{|c|c|c|c|c|c|}
\hline Authors \& Year & $\begin{array}{l}\text { Study Population } \\
\text { (aneurysm condition) }\end{array}$ & $\begin{array}{l}\text { Included } \\
\text { Cases }\end{array}$ & $\begin{array}{l}\text { Pts w/ De Novo } \\
\text { Aneurysms }\end{array}$ & $\begin{array}{c}\text { Mean Follow-Up } \\
\text { (yrs) }\end{array}$ & Study Design \\
\hline Wang et al., 2015 & Ruptured \& unruptured* & 185 & 9 & 3.3 & Retrospective \\
\hline Ferns et al., 2011 & Ruptured & 276 & 2 & 4.8 & Prospective \\
\hline Goksu et al., 2015 & Ruptured & 117 & 1 & 6.1 & Retrospective \\
\hline Wermer et al., 2005 & Ruptured & 610 & 14 & 9.1 & Prospective \\
\hline van der Schaaf et al., 2005 & Ruptured & 495 & 13 & 8.6 & Prospective \\
\hline Kemp et al., 2013 & Ruptured \& unruptured & 611 & 37 & 8.3 & Retrospective \\
\hline Serrone et al., 2016 & Unruptured & 192 & 4 & 3.9 & Prospective \\
\hline Yoneoka et al., 2004 & Ruptured & 483 & 12 & 10.7 & Prospective \\
\hline Tsutsumi et al., 2001 & Ruptured \& unruptured* & 112 & 9 & 8.3 & Prospective \\
\hline Phan et al., 2002 & Unruptured & 57 & 0 & 3.9 & Retrospective \\
\hline Burkhardt et al., 2017 & Ruptured \& unruptured* & 240 & 8 & 6 & Retrospective \\
\hline Brown et al., 2017 & Ruptured \& unruptured & 616 & 8 & 7.2 & Retrospective \\
\hline Lindgren et al., 2016 & Ruptured \& unruptured* & 1419 & 42 & 11.7 & Prospective \\
\hline Lecler et al., 2015 & Ruptured & 112 & 11 & 11.1 & Prospective \\
\hline Bor et al., 2014 & Ruptured \& unruptured & 910 & 18 & 14 & Retrospective \\
\hline Kim et al., 2013 & Ruptured \& unruptured & 107 & 1 & 14 & Retrospective \\
\hline Lindvall et al., 2012 & Ruptured \& unruptured & 44 & 0 & 9.7 & Prospective \\
\hline Sprengers et al., 2009 & Ruptured \& unruptured & 65 & 1 & 5.1 & Retrospective \\
\hline Edner \& Almqvist, 2007 & Ruptured & 102 & 7 & 19.8 & Prospective \\
\hline Porter et al., 2001 & Ruptured & 122 & 1 & 1.1 & Prospective \\
\hline Miller et al., 1985 & Ruptured \& unruptured & 620 & 7 & 16 & Prospective \\
\hline Akyüz et al., 2004 & Ruptured & 136 & 2 & 3.9 & Prospective \\
\hline Lai et al., 2004 & Ruptured \& unruptured* & 472 & 33 & 4.5 & Retrospective \\
\hline Plowman et al., 2011 & Ruptured \& unruptured* & 452 & 1 & 6.1 & Retrospective \\
\hline Molyneux et al., 2009 & Ruptured & 2143 & 6 & 7.8 & Retrospective \\
\hline Juvela et al., 1993 & Unruptured & 142 & 6 & 13.7 & Retrospective \\
\hline Bruneau et al., 2011 & Ruptured & 20 & 6 & 18 & Prospective \\
\hline Miyazawa et al., 2006 & Unruptured & 130 & 3 & 2.4 & Retrospective \\
\hline Rinne \& Hernesniemi, 1993 & Ruptured \& unruptured & 1150 & 13 & 15.5 & Prospective \\
\hline Sakaki et al., 1993 & Ruptured & 986 & 9 & 5.7 & Retrospective \\
\hline Gallas et al., 2009 & Ruptured \& unruptured & 1036 & 5 & 4.47 & Prospective \\
\hline Holmin et al., 2008 & Ruptured \& unruptured & 466 & 3 & 5.36 & Retrospective \\
\hline Zali et al., 2014 & Ruptured & 127 & 9 & 7.2 & Retrospective \\
\hline David et al., 1999 & Unruptured & 102 & 6 & 4.4 & Retrospective \\
\hline Matsumoto et al., 2013 & Unruptured & 111 & 2 & 2.5 & Retrospective \\
\hline
\end{tabular}

${ }^{\text {* } D a t a ~ r e g a r d i n g ~ r u p t u r e d ~ a n d ~ u n r u p t u r e d ~ a n e u r y s m s . ~}$

length of follow-up ( $>5$ years). Based on these criteria, studies were divided into "high" and "low" risk of bias and a separate analysis was done comparing the 2 tiers to see whether there was any statistically significant difference.

\section{Statistical Analysis}

We estimated from each cohort the event rate in order to estimate the overall incidence and the incidence density (reported as number of de novo aneurysms formed per patient-year of follow-up). Estimates from each cohort were pooled in a random-effects model meta-analysis as described by DerSimonian and Laird. Anticipating heterogeneity between studies, we chose this model a priori because it incorporates within-study variance and between-study variance. Proportions of individuals with de novo aneurysm formation were compared for risk factor prevalence using a chi-square test.

\section{Results}

\section{Literature Search and Study Characteristics}

The initial literature search yielded 772 articles. Upon review of abstracts and titles, 689 articles were excluded. On secondary review, an additional 48 articles were excluded because they did not match the eligibility criteria for this meta-analysis, including length of follow-up or 
TABLE 2. Methodological quality evaluation of included studies

\begin{tabular}{|c|c|c|c|c|c|c|c|}
\hline \multirow[b]{2}{*}{ Authors \& Year } & \multicolumn{4}{|c|}{ Selection } & \multicolumn{3}{|c|}{ Outcome } \\
\hline & $\begin{array}{l}\text { Representativeness } \\
\text { of Exposed Cohort }\end{array}$ & $\begin{array}{c}\text { Selection of } \\
\text { Non-Exposed } \\
\text { Cohort }\end{array}$ & $\begin{array}{l}\text { Ascertainment } \\
\text { of Exposure }\end{array}$ & $\begin{array}{l}\text { Demonstration of } \\
\text { Outcome of Interest } \\
\text { Was Not Present at } \\
\text { Beginning }\end{array}$ & $\begin{array}{l}\text { Assessment } \\
\text { of Outcome }\end{array}$ & $\begin{array}{l}\text { Length of } \\
\text { Follow-Up } \\
\text { ( } \geq 5 \text { yrs) }\end{array}$ & $\begin{array}{c}\text { Adequacy of } \\
\text { Follow-Up } \\
\text { (CTA, MRA, } \\
\text { DSA) }\end{array}$ \\
\hline Wermer et al., 2005 & * & * & * & * & * & * & * \\
\hline Lecler et al., 2015 & * & * & * & * & * & * & * \\
\hline Sprengers et al., 2009 & * & * & * & * & * & * & * \\
\hline Molyneux et al., 2009 & * & * & * & * & * & * & * \\
\hline Juvela et al., 1993 & * & * & * & * & * & * & * \\
\hline Bruneau et al., 2011 & * & * & * & * & * & * & * \\
\hline Rinne \& Hernesniemi, 1993 & * & * & * & * & * & * & * \\
\hline Gallas et al., 2009 & * & * & * & * & * & * & * \\
\hline Wang et al., 2015 & * & * & * & * & * & & * \\
\hline Goksu et al., 2015 & * & * & * & * & * & * & \\
\hline van der Schaaf et al., 2005 & * & * & * & * & * & * & \\
\hline Serrone et al., 2016 & * & * & * & * & * & & * \\
\hline Yoneoka et al., 2004 & * & * & * & * & * & * & * \\
\hline Tsutsumi et al., 2001 & * & * & * & * & * & * & \\
\hline Brown et al., 2017 & * & * & * & * & * & * & \\
\hline Lindgren et al., 2016 & * & * & * & * & * & * & * \\
\hline Bor et al., 2014 & * & * & * & * & * & * & \\
\hline Lindvall et al., 2012 & * & * & * & * & * & * & \\
\hline Edner \& Almqvist, 2007 & * & * & & * & * & * & * \\
\hline Akyüz et al., 2004 & * & * & * & * & * & & * \\
\hline Plowman et al., 2011 & * & * & * & * & * & * & * \\
\hline Sakaki et al., 1993 & * & * & * & * & * & * & \\
\hline Zali et al., 2014 & * & * & * & * & * & * & \\
\hline David et al., 1999 & * & * & * & * & * & & * \\
\hline Ferns et al., 2011 & * & * & * & * & * & & \\
\hline Kemp et al., 2013 & * & * & * & * & * & * & \\
\hline Phan et al., 2002 & * & * & * & * & * & & * \\
\hline Burkhardt et al., 2017 & * & * & * & * & * & * & \\
\hline Lai et al., 2004 & * & * & * & * & * & & \\
\hline Matsumoto et al., 2013 & * & * & * & & * & & * \\
\hline Miyazawa et al., 2006 & * & * & * & & * & & \\
\hline Miller et al., 1985 & * & * & * & * & * & * & \\
\hline Holmin et al., 2008 & * & * & * & & * & * & \\
\hline Kim et al., 2013 & & & * & * & * & * & \\
\hline Porter et al., 2001 & & * & * & * & * & & \\
\hline
\end{tabular}

Asterisk $\left(^{*}\right)$ indicates that the study fulfilled the specified criterion.

adequate definition for de novo aneurysms. In total, 35 studies describing the rate of de novo aneurysm formation were included; these studies included 14,968 patients. Seven of these 35 studies reported the incidence of de novo aneurysms specifically for patients with unruptured aneurysms, while 14 studies concerned exclusively patients with ruptured aneurysms. The mean duration of patient followup was 8.1 years, and the median was 7.2 years. Nineteen studies were retrospective and 16 were prospective. Of the 35 studies included in our meta-analysis, 18 had a high risk of bias and 17 had a low risk of bias. A study-selection flow diagram compiled following the PRISMA guidelines is provided in Fig. 1..$^{32}$ A summary of the included studies is provided in Table 1. Methodological quality indicators are summarized in Table 2. Overall, these noncomparative series appeared to have adequate quality.

\section{Incidence of De Novo Aneurysm Formation}

The overall incidence of de novo aneurysm formation 


\begin{tabular}{|c|c|c|c|}
\hline Author, Year & $\begin{array}{l}\mathrm{N} \\
\text { Event } \\
\text { (patients) }\end{array}$ & $\begin{array}{l}\mathrm{N} \\
\text { Total }\end{array}$ & $\mathrm{ES}(95 \% \mathrm{Cl})$ \\
\hline Wang et al., 2015 & 9 & 185 & $0.05(0.03,0.09)$ \\
\hline Ferns et al., 2011 & 2 & 276 & $0.01(0.00,0.03)$ \\
\hline Goksu et al., 2015 & 1 & 117 & $0.01(0.00,0.05)$ \\
\hline Wermer et al., 2005 & 14 & 610 & $0.02(0.01,0.04)$ \\
\hline van der Schaaf et al., 2005 & 13 & 495 & $0.03(0.02,0.04)$ \\
\hline Kemp et al., 2013 & 37 & 611 & $0.06(0.04,0.08)$ \\
\hline Serrone et al., 2016 & 4 & 192 & $0.02(0.01,0.05)$ \\
\hline Yoneoka et al., 2004 & 12 & 483 & $0.02(0.01,0.04)$ \\
\hline Tsutsumi et al., 2001 & 9 & 112 & $0.08(0.04,0.15)$ \\
\hline Phan et al., 2002 & 0 & 57 & $0.00(0.00,0.06)$ \\
\hline Burkhardt et al., 2017 & 8 & 240 & $0.03(0.02,0.06)$ \\
\hline Brown et al., 2016 & 8 & 616 & $0.01(0.01,0.03)$ \\
\hline Lindgren et al., 2016 & 42 & 1419 & $0.03(0.02,0.04)$ \\
\hline Lecler et al., 2015 & 11 & 112 & $0.10(0.06,0.17)$ \\
\hline Bor et al., 2014 & 18 & 910 & $0.02(0.01,0.03)$ \\
\hline Kim et al, 2013 & 1 & 107 & $0.01(0.00,0.05)$ \\
\hline Lindvall et al., 2012 & 0 & 44 & $0.00(0.00,0.08)$ \\
\hline Sprengers et al., 2009 & 1 & 65 & $0.02(0.00,0.08)$ \\
\hline Edner et al.,2007 & 7 & 102 & $0.07(0.03,0.13)$ \\
\hline Porter et al.,2001 & 1 & 122 & $0.01(0.00,0.04)$ \\
\hline Miller et al., 1985 & 7 & 620 & $0.01(0.01,0.02)$ \\
\hline Akyuz et al., 2004 & 2 & 136 & $0.01(0.00,0.05)$ \\
\hline Lai et al., 2004 & 33 & 472 & $0.07(0.05,0.10)$ \\
\hline Plowman et al., 2011 & 1 & $452 \bullet$ & $0.00(0.00,0.01)$ \\
\hline Molyneux et al., 2009 & 6 & 2143 & $0.00(0.00,0.01)$ \\
\hline Juvela et al., 1993 & 6 & 142 & $0.04(0.02,0.09)$ \\
\hline Bruneau et al., 2011 & 6 & 20 & $0.30(0.15,0.52)$ \\
\hline Miyazawa et al., 2006 & 3 & 130 & $0.02(0.01,0.07)$ \\
\hline Rinne et al., 1993 & 13 & 1150 & $0.01(0.01,0.02)$ \\
\hline Sakaki et al., 1993 & 9 & 986 & $0.01(0.00,0.02)$ \\
\hline Gallas et al., 2009 & 5 & 1036 & $0.00(0.00,0.01)$ \\
\hline Holmin et al., 2008 & 3 & 466 & $0.01(0.00,0.02)$ \\
\hline Zali et al., 2014 & 9 & 127 & $0.07(0.04,0.13)$ \\
\hline David et al., 1999 & 6 & 102 & $0.06(0.03,0.12)$ \\
\hline Matsumoto et al, 2013 & 2 & 111 & $0.02(0.00,0.06)$ \\
\hline \multirow[t]{2}{*}{ Overall $\left(\left.\right|^{\wedge} 2=87.05 \%, p=0.00\right)$} & & & $0.02(0.02,0.03)$ \\
\hline & & & \\
\hline
\end{tabular}

FIG. 2. Forest plot for overall incidence of de novo aneurysms. ES = effect size. Figure is available in color online only.

was $2 \%(95 \%$ CI $2 \%-3 \%)$ during a mean follow-up of 8.1 years (Fig. 2), while the incidence density (person-time incidence rate) was estimated to be $0.30 \%$ /patient-year $(95 \%$ CI $0.21 \%-0.42 \% /$ patient-year) (Fig. 3).

When considering patients with a history of ruptured aneurysm, the incidence of a de novo aneurysm was 3\% over a mean follow-up time of 8.5 years $(95 \%$ CI $2 \%-5 \%)$ (Fig. 4), and the incidence density was estimated to be $0.4 \%$ / patient-year (95\% CI 0.2\%-0.6\%/patient-year) (Fig. 5).

When considering patients with a history of unruptured aneurysm, the incidence of a de novo aneurysm was 3\% for a mean follow-up of 5.8 years (95\% CI 2\%-5\%) (Fig. $6)$, while the incidence density was estimated to be $0.6 \%$ / patient-year (95\% CI 0.35\%-0.88\%/patient-year) (Fig. 7).

There was no significant difference in the rate of de novo aneurysm formation between ruptured and unruptured aneurysm populations.

\section{Timing of De Novo Aneurysm Formation}

Information regarding the timing of de novo aneurysm formation was reported in 27 studies (involving 268 patients with de novo aneurysms). The mean time to identification of a de novo aneurysm in these studies was 8.3 years. In 8 studies, $11.2 \%$ of de novo aneurysms were found in patients with $\leq 5$ years of follow-up and
$88.8 \%$ were found at $>5$ years. Fifteen studies (involving 117 patients with de novo aneurysms) described the treatment for the discovered de novo aneurysms; in 97 (83\%) of the reported 117 cases in these studies, the de novo aneurysms were treated with surgical or endovascular techniques.

\section{Timing of De Novo Aneurysm Rupture}

Information regarding the timing of de novo aneurysm rupture was reported in 26 studies, with 55 patients experiencing rupture over a mean follow-up time of 10.8 years (range 5.3-16 years). Of these 55 patients, 32 (58\%) experienced rupture of their de novo aneurysm after more than 10 years.

\section{Risk Factors for De Novo Aneurysm Formation}

Six studies reported information about smoking habits. The proportion of current or prior smokers was $38.8 \%$ among patients who did not develop de novo aneurysm during follow-up and $55.8 \%$ among those who were found to have a new aneurysm on follow-up imaging ( $\mathrm{p}<0.01)$.

Five studies reported details about a diagnosis of hypertension for their patients. Fifty-four percent of patients who did not develop de novo aneurysms had a diagnosis of 


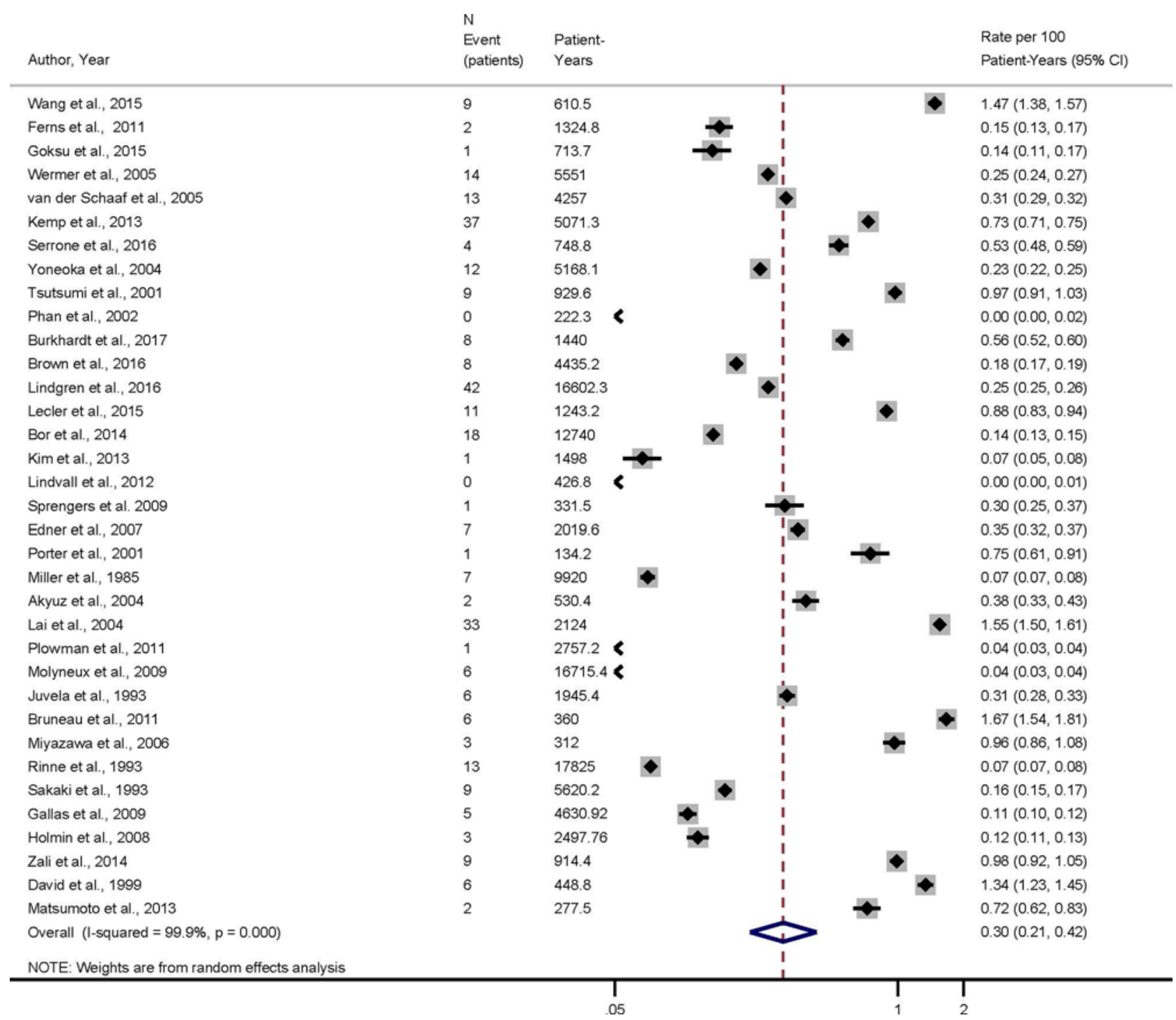

FIG. 3. Forest plot for overall incidence density for de novo aneurysms. Figure is available in color online only.

hypertension compared to $40 \%$ of those who were found to have a new aneurysm on follow-up imaging $(p=0.43)$.

Presence of multiple aneurysms at initial diagnosis was documented in 7 studies. The proportion of multiple aneurysms was $32.3 \%$ among patients who did not develop de novo aneurysm during follow-up and $46.5 \%$ among those who were found to have a new aneurysm on follow-up imaging $(\mathrm{p}=0.01)$.

Family history of intracranial aneurysms was documented in 6 studies. The proportion of patients with a familial history of intracranial aneurysms was $16.1 \%$ among patients who did not develop a de novo aneurysm during follow-up and $30.8 \%$ among those who were found to have a new aneurysm on follow-up imaging $(\mathrm{p}<0.01)$.

Sex was documented in 20 studies. The proportion of women was $61.4 \%$ among patients who did not develop a de novo aneurysm during follow-up versus $71.6 \%$ among those who were found to have a new aneurysm $(p=0.02)$.

Age at presentation was reported in 27 studies. We arbitrarily choose 50 years as the threshold to evaluate whether young $(<50$ years) or older ( $\geq 50$ years) age was a risk factor for aneurysm development. The proportion of patients older than 50 years was $66 \%$ among patients who did not develop a de novo aneurysm during follow-up and $69.7 \%$ among those who were found to have a new aneurysm $(\mathrm{p}=0.2)$.

\section{Discussion}

In this systematic review and meta-analysis of 35 studies involving nearly 15,000 patients, we found a $2 \%$ incidence rate of de novo aneurysm formation in patients with a prior diagnosis of ruptured or unruptured aneurysm after a mean follow-up time of more than 8 years. The overall rate of aneurysm formation was less than $0.5 \%$ / patient-year. There was no statistically significant difference in the rate of de novo aneurysm formation in patients with ruptured or unruptured aneurysms. A clear majority 


\begin{tabular}{|c|c|c|c|}
\hline Author, Year, Population & $\begin{array}{l}\mathrm{N} \\
\text { Event } \\
\text { (patients) }\end{array}$ & $\begin{array}{l}\mathrm{N} \\
\text { Total }\end{array}$ & ES $(95 \% \mathrm{Cl})$ \\
\hline Wang et al., 2015, ruptured & 6 & 96 & $0.06(0.03,0.13)$ \\
\hline Ferns et al., 2011, ruptured & 2 & 235 & $0.01(0.00,0.03)$ \\
\hline Goksu et al., 2015, ruptured & 1 & 108 & $0.01(0.00,0.05)$ \\
\hline Wermer et al., 2005, ruptured & 14 & 610 & $0.02(0.01,0.04)$ \\
\hline van der Schaaf et al., 2005, ruptured & 13 & 495 & $0.03(0.02,0.04)$ \\
\hline Yoneoka et al., 2004, ruptured & 12 & 483 & $0.02(0.01,0.04)$ \\
\hline Tsutsumi et al., 2001, ruptured & 5 & 88 & $0.06(0.02,0.13)$ \\
\hline Burkhardt et al., 2017, ruptured & 5 & 90 & $0.06(0.02,0.12)$ \\
\hline Lindgren et al., 2016, ruptured & 28 & 1094 & $0.03(0.02,0.04)$ \\
\hline Lecler et al., 2015, ruptured & 11 & 112 & $0.10(0.06,0.17)$ \\
\hline Edner et al., 2007, ruptured & 7 & 102 & $0.07(0.03,0.13)$ \\
\hline Porter et al., 2001, ruptured & 1 & 99 & $0.01(0.00,0.06)$ \\
\hline Akyüz et al., 2004, ruptured & 2 & 136 & $0.01(0.00,0.05)$ \\
\hline Lai et al., 2004, ruptured & 17 & 137 & $0.12(0.08,0.19)$ \\
\hline Plowan et al., 2011, ruptured & 1 & $570<$ & $0.00(0.00,0.01)$ \\
\hline Molyneux et al., 2009, ruptured & 6 & $2143<$ & $0.00(0.00,0.01)$ \\
\hline Bruneau et al., 2011, ruptured & 6 & 20 & $0.30(0.15,0.52)$ \\
\hline Sakaki et al., 1993, ruptured & 9 & 986 & $0.01(0.00,0.02)$ \\
\hline Zali et al., 2014, ruptured & 9 & 127 & $0.07(0.04,0.13)$ \\
\hline Overall $\left(\wedge^{\wedge} 2=89.89 \%, p=0.00\right)$ & & & $0.03(0.02,0.05)$ \\
\hline
\end{tabular}

FIG. 4. Forest plot for the incidence of de novo aneurysmal after aneurysmal SAH. Figure is available in color online only.

$(>80 \%)$ of de novo aneurysms discovered in this study were found at more than 5 years of follow-up. No patient presented with rupture of a de novo aneurysm earlier than 10 years after diagnosis of the original aneurysm. Moreover, the results of a secondary analysis considering highversus low-quality studies were not significantly different from the results of the primary analysis. Risk factors for de novo aneurysm formation included family history of aneurysm, aneurysm multiplicity, female sex, and smoking status. These findings are important as they suggest that routine screening for de novo aneurysms is likely of low yield and could be performed at time intervals of at least 5 to 10 years, with more frequent screening possibly indicated for patients with certain risk factors.

Based on this systematic review and meta-analysis, there is wide variability in the rate of de novo aneurysm formation across single-center series, ranging from $0.1 \%$ to $2 \%$ per year. ${ }^{9,11}$ Among patients with a ruptured aneurysm, the rate of de novo aneurysm formation ranges from $0.05 \%$ to $2.8 \%$ annually based on single-center studies, $18,27,28,31,34,37$ while studies of patients with unruptured aneurysms show rates of $0 \%-2 \%$ per year. ${ }^{19,24,30}$ Our study demonstrates that the rate of de novo aneurysm formation is well below $1 \%$ per year, with a narrow confidence interval, regardless of rupture status. These findings are particularly important for counseling patients with a prior, successfully treated, aneurysm.
Risk factors that have been studied for de novo aneurysm formation include hypertension, age, cigarette smoking, history of prior SAH, aneurysm multiplicity, and aneurysm location. ${ }^{22,29}$ Among series evaluated in our meta-analysis, smoking was significantly associated with de novo aneurysm formation in 7 studies, ${ }^{2,3,12,14,15,17,36}$ history of previous aneurysmal SAH in 6 studies, ${ }^{2-4,14,22}$ and multiplicity in 4 studies., ${ }^{3,620,22}$ Hypertension was described as a significant risk factor in one study..$^{14}$ In our systematic review, we found that that the majority of patients who developed a new aneurysm were active or former smokers, were female, and had a positive familial history for intracranial aneurysms, while we did not find age to be a risk factor. The contributions of age and sex to the risk of developing a de novo aneurysm are controversial. Age was not found to be associated with de novo aneurysm formation in 5 studies ${ }^{3-5,19,38}$ while it was a risk factor in two. ${ }^{16,24}$ In accordance with our findings, female sex was found to be a risk factor for de novo aneurysm formation in 7 studies, ${ }^{1,10,12,13,34-36}$ although in 5 studies no association could be documented. $6,17,30,33,39$ The reasons for a higher risk of new aneurysm formation in women are unknown.

Another important finding from this study was the time to de novo aneurysm detection. The mean time to discovery of a de novo aneurysm in our study was $>8$ years and the mean time to rupture for those who experienced rupture was $>10$ years. The overall time range of 


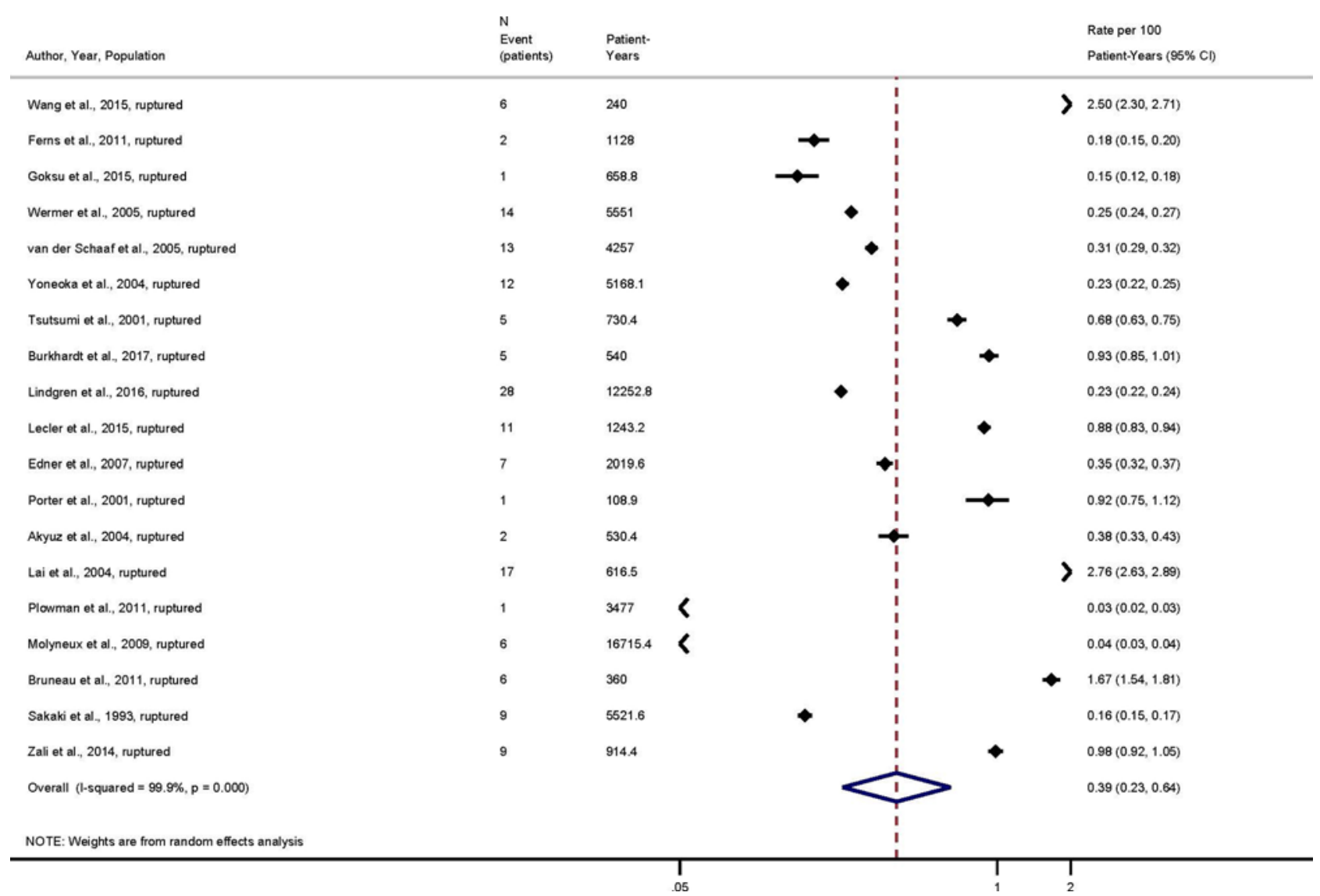

FIG. 5. Forest plot for the incidence density of de novo aneurysm formation in patients with prior aneurysmal SAH. Figure is available in color online only.

de novo aneurysm detection reported in the literature is roughly 3-15 years after identification of the index aneurysm. ., $, 12,21,33,36,38$ The major concern for patients who are diagnosed with an aneurysm is the risk of rupture. Longterm follow-up data from ISAT (International Subarachnoid Aneurysm Trial) suggest an annual rupture rate from de novo aneurysms in patients with a coiled aneurysm of $0.04 \%-0.06 \%{ }^{23,28}$ Given the fact that our meta-analysis found that de novo aneurysms form and rupture around the 10 -year time point, our findings suggest that screening for the presence of these lesions can be performed at 5- to 10 -year intervals..$^{16,25}$

The findings from the current analysis should be taken in the context of the goal of screening brain aneurysm patients-preventing aneurysmal SAH. ${ }^{26,31}$ A number of studies have demonstrated that routine screening of most intracranial aneurysm populations is not cost-effective. ${ }^{1,6,8,31,37}$ Meanwhile, others have suggested that because SAH from de novo aneurysms can occur at any time point, increased screening frequency, particularly for individuals with a family history of aneurysmal SAH, is needed..$^{2,3,15,20,39}$ In a cost-effectiveness analysis study on periodic screening for detection of de novo aneurysms in patients with a history of SAH treated with clipping, Ferns et al. found that screening was not cost-effective, mostly because of screening-induced fear in patients. ${ }^{8}$ These results were confirmed in a later decision-analysis study on the effectiveness of screening for de novo aneurysm in patients treated for a ruptured intracranial aneurysm, concluding that screening cannot be recommended. ${ }^{34,36}$ Given the rarity of de novo aneurysm formation and rupture, our findings corroborate those of these previously published cost-effectiveness and decision tree analyses. However, based on the results of our meta-analysis, it may be reasonable to restrict followup imaging for de novo aneurysm formation at intervals of 5 years to patients who are active smokers, have a family history of intracranial aneurysms, or have been diagnosed with multiple aneurysms.

\section{Strengths and Limitations}

The strengths of our study include following an a priori established protocol, a comprehensive literature search that involved multiple databases, and the process of study selection performed by independent reviewers. The main limitation of this analysis is the lack of individual patient data, which makes prognostic analysis subject to confounding and ecologic bias. De novo aneurysms were assessed with various imaging modalities, including CTA, DSA, and MRA, which could introduce some error or bias, along with the possibility of inter- and intraobserver variability in assessing true de novo aneurysms. Follow- 


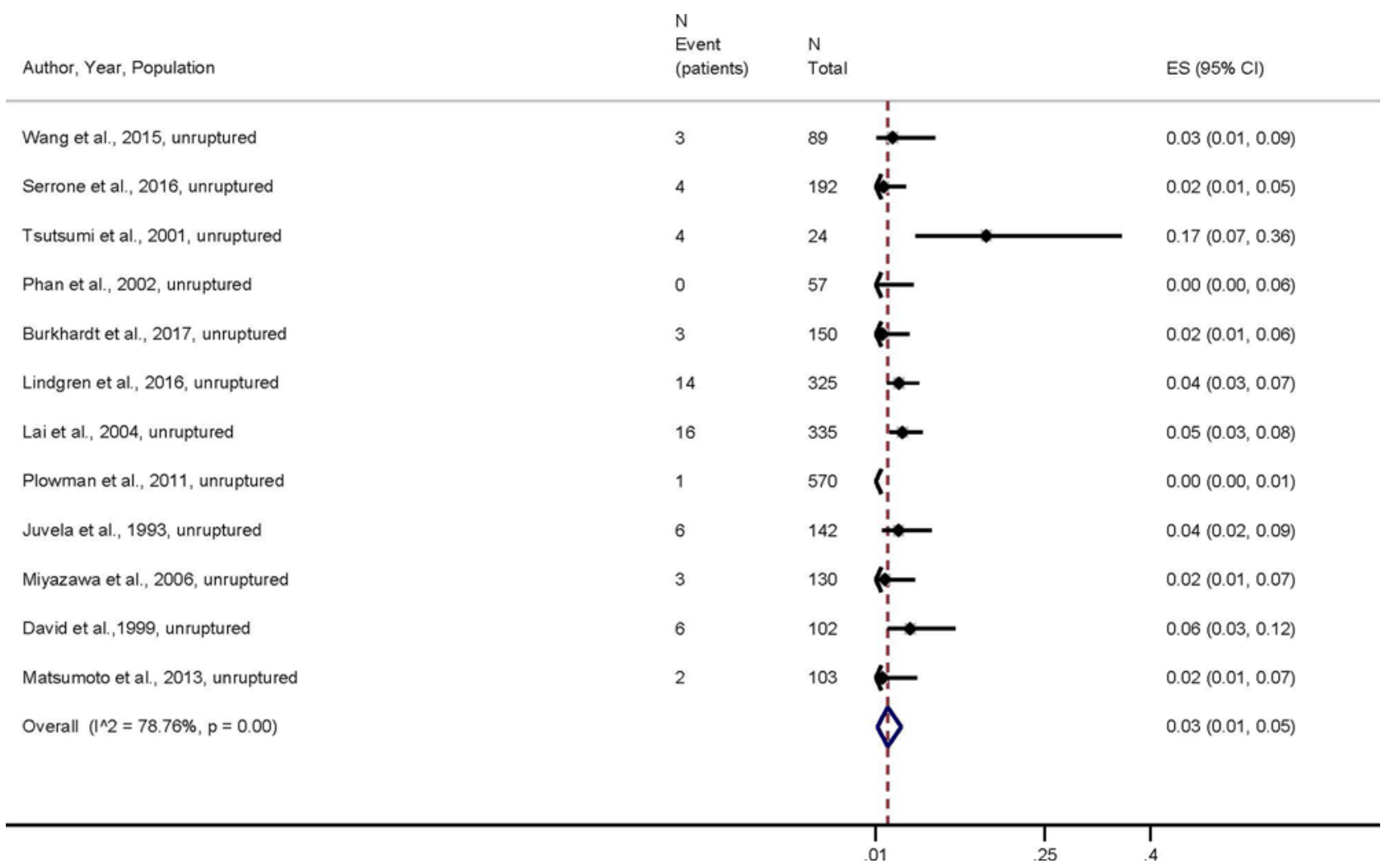

FIG. 6. Forest plot for the incidence of de novo aneurysm in patients with unruptured aneurysms. Figure is available in color online only.

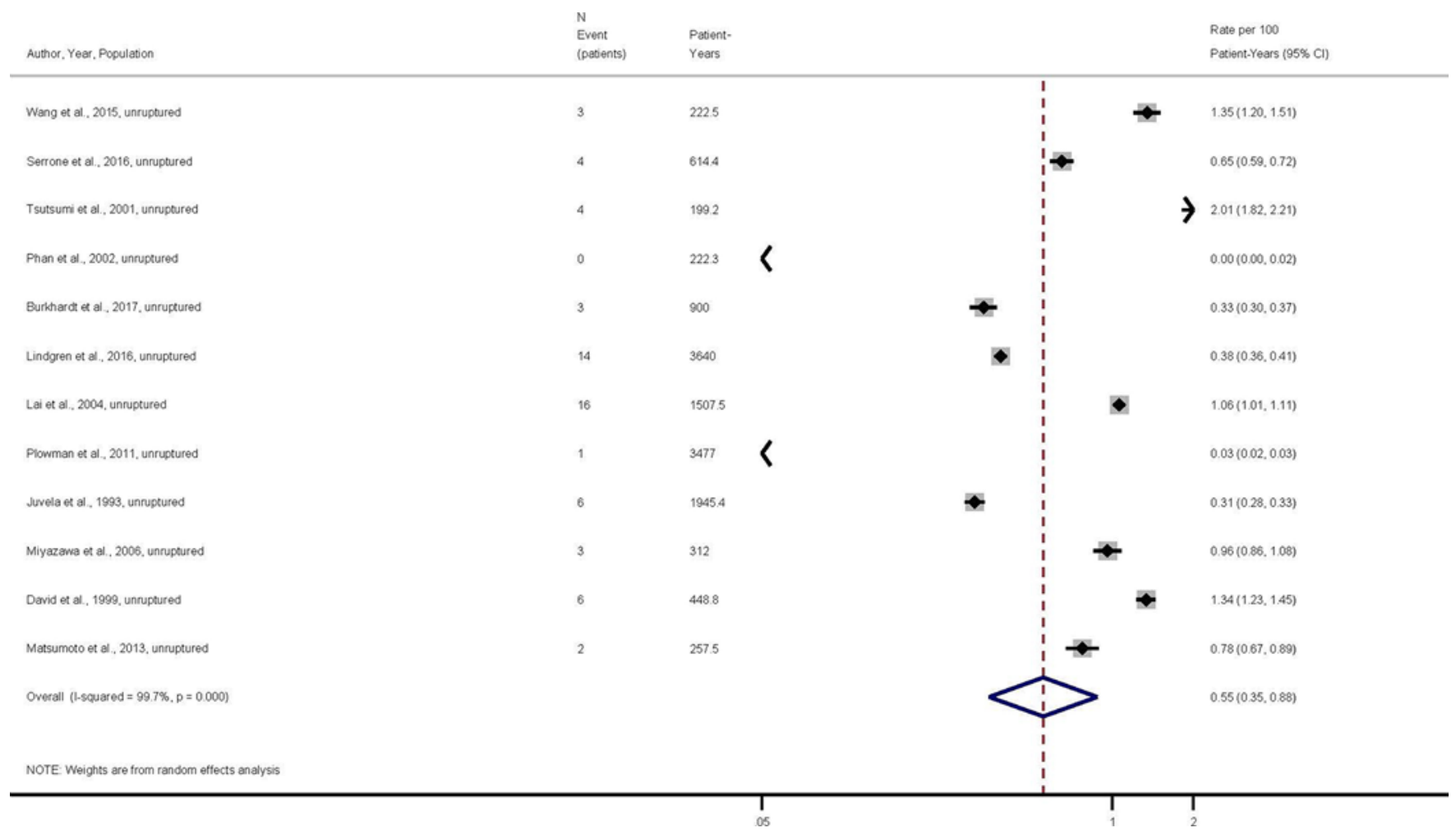

FIG. 7. Forest plot for the incidence density of de novo aneurysm in patients with a diagnosis of unruptured aneurysm. Figure is available in color online only. 
up times were variable across studies and few studies had mean follow-up times of 10 years or greater. Thus, we could be underestimating the rate of de novo aneurysm formation. There are no reliable methods to ascertain the presence of publication bias in noncomparative series; however, publication bias remains possible.

\section{Conclusions}

This systematic review and meta-analysis including nearly 15,000 intracranial aneurysm patients who received imaging follow-up for evaluation of de novo aneurysm formation demonstrates that approximately $2 \%$ of intracranial aneurysm patients develop a de novo aneurysm, with an estimated cumulative incidence of $0.3 \%$ /patient-year. We found no difference in rates of de novo aneurysm formation among patients with ruptured aneurysms and those with unruptured aneurysms. A vast majority of de novo aneurysms were found at more than 5 years after diagnosis of the index aneurysm and few ruptured. Among those aneurysms that ruptured, the mean time to rupture was greater than 10 years. These findings suggest that when appropriate, de novo aneurysm screening can be performed at roughly 5 - to 10 -year intervals.

\section{References}

1. Akyüz M, Tuncer R, Yilmaz S, Sindel T: Angiographic follow-up after surgical treatment of intracranial aneurysms. Acta Neurochir (Wien) 146:245-250, 2004

2. Bor AS, Rinkel GJ, van Norden J, Wermer MJ: Long-term, serial screening for intracranial aneurysms in individuals with a family history of aneurysmal subarachnoid haemorrhage: a cohort study. Lancet Neurol 13:385-392, 2014

3. Brown MA, Parish J, Guandique CF, Payner TD, Horner $\mathrm{T}$, Leipzig T, et al: A long-term study of durability and risk factors for aneurysm recurrence after microsurgical clip ligation. J Neurosurg 126:819-824, 2017

4. Bruneau M, Rynkowski M, Smida-Rynkowska K, Brotchi J, De Witte O, Lubicz B: Long-term follow-up survey reveals a high yield, up to $30 \%$ of patients presenting newly detected aneurysms more than 10 years after ruptured intracranial aneurysms clipping. Neurosurg Rev 34:485-496, 2011

5. Burkhardt JK, Chua MHJ, Weiss M, Do ASS, Winkler EA, Lawton MT: Risk of aneurysm residual regrowth, recurrence, and de novo aneurysm formation after microsurgical clip occlusion based on follow-up with catheter angiography. World Neurosurg 106:74-84, 2017

6. David CA, Vishteh AG, Spetzler RF, Lemole M, Lawton MT, Partovi S: Late angiographic follow-up review of surgically treated aneurysms. J Neurosurg 91:396-401, 1999

7. Edner G, Almqvist H: The Stockholm 20-year follow-up of aneurysmal subarachnoid hemorrhage outcome. Neurosurgery 60:1017-1024, 2007

8. Ferns SP, Sprengers ME, van Rooij WJ, van den Berg R, Velthuis BK, de Kort GA, et al: De novo aneurysm formation and growth of untreated aneurysms: a 5-year MRA follow-up in a large cohort of patients with coiled aneurysms and review of the literature. Stroke 42:313-318, 2011

9. Gallas S, Januel AC, Pasco A, Drouineau J, Gabrillargues J, Gaston A, et al: Long-term follow-up of 1036 cerebral aneurysms treated by bare coils: a multicentric cohort treated between 1998 and 2003. AJNR Am J Neuroradiol 30:19861992, 2009

10. Goksu E, Korkmaz E, Akyuz M, Ozgur O, Sindel T, Tuncer $\mathrm{R}$ : The analysis of long-term follow-up screening in patients with surgically treated intracranial aneurysms. Turk Neurosurg 25:404-409, 2015

11. Holmin S, Krings T, Ozanne A, Alt JP, Claes A, Zhao W, et al: Intradural saccular aneurysms treated by Guglielmi detachable bare coils at a single institution between 1993 and 2005: clinical long-term follow-up for a total of 1810 patientyears in relation to morphological treatment results. Stroke 39:2288-2297, 2008

12. Juvela S, Porras M, Heiskanen O: Natural history of unruptured intracranial aneurysms: a long-term follow-up study. J Neurosurg 79:174-182, 1993

13. Kemp WJ III, Fulkerson DH, Payner TD, Leipzig TJ, Horner TG, Palmer EL, et al: Risk of hemorrhage from de novo cerebral aneurysms. J Neurosurg 118:58-62, 2013

14. Kim ST, Jeong HW, Jeong YG, In HS: Coiling as retreatment in intracranial aneurysm of de novo formation or regrowth: case report. Neurointervention 8:46-51, 2013

15. Lai LT, Morgan MK, Patel NJ: Smoking increases the risk of de novo intracranial aneurysms. World Neurosurg 82:e195e201, 2014

16. Lecler A, Raymond J, Rodriguez-Régent C, Al Shareef F, Trystram D, Godon-Hardy S, et al: Intracranial aneurysms: recurrences more than 10 years after endovascular treatment-a prospective cohort study, systematic review, and meta-analysis. Radiology 277:173-180, 2015

17. Lindgren AE, Räisänen S, Björkman J, Tattari H, Huttunen $\mathrm{J}$, Huttunen T, et al: De novo aneurysm formation in carriers of saccular intracranial aneurysm disease in eastern Finland. Stroke 47:1213-1218, 2016

18. Lindvall P, Borota L, Birgander R, Jonasson P, Ridderheim PA: Long-term follow-up of intracranial aneurysms treated with endovascular coiling: experience from one institution. Vasc Endovascular Surg 46:325-328, 2012

19. Matsumoto E, Masuzawa T, Nakamura Y: Long-term outcome of unruptured cerebral aneurysms. J Epidemiol 13:289-295, 2003

20. Matsumoto K, Oshino S, Sasaki M, Tsuruzono K, Taketsuna $\mathrm{S}$, Yoshimine T: Incidence of growth and rupture of unruptured intracranial aneurysms followed by serial MRA. Acta Neurochir (Wien) 155:211-216, 2013

21. Miller CA, Hill SA, Hunt WE: "De novo" aneurysms. A clinical review. Surg Neurol 24:173-180, 1985

22. Miyazawa N, Akiyama I, Yamagata Z: Risk factors for growth of unruptured intracranial aneurysms: follow-up study by serial 0.5-T magnetic resonance angiography. Neurosurgery 58:1047-1053, 2006

23. Molyneux AJ, Kerr RS, Birks J, Ramzi N, Yarnold J, Sneade M, et al: Risk of recurrent subarachnoid haemorrhage, death, or dependence and standardised mortality ratios after clipping or coiling of an intracranial aneurysm in the International Subarachnoid Aneurysm Trial (ISAT): long-term follow-up. Lancet Neurol 8:427-433, 2009

24. Phan TG, Huston J III, Brown RD Jr, Wiebers DO, Piepgras DG: Intracranial saccular aneurysm enlargement determined using serial magnetic resonance angiography. J Neurosurg 97:1023-1028, 2002

25. Plowman RS, Clarke A, Clarke M, Byrne JV: Sixteen-year single-surgeon experience with coil embolization for ruptured intracranial aneurysms: recurrence rates and incidence of late rebleeding. Clinical article. J Neurosurg 114:863874, 2011

26. Porter PJ, Mazighi M, Rodesch G, Alvarez H, Aghakhani N, David PH, et al: Endovascular and surgical management of multiple intradural aneurysms. Review of 122 patients managed between 1993 and 1999. Interv Neuroradiol 7:291302, 2001

27. Rahmah NN, Horiuchi T, Kusano Y, Sasaki T, Hongo K: De novo aneurysm: case reports and literature review. Neurosurgery 69:E761-E767, 2011 
28. Rinne JK, Hernesniemi JA: De novo aneurysms: special multiple intracranial aneurysms. Neurosurgery 33:981-985, 1993

29. Sakaki T, Tominaga M, Miyamoto K, Tsunoda S, Hiasa Y: Clinical studies of de novo aneurysms. Neurosurgery 32:512-517, 1993

30. Serrone JC, Tackla RD, Gozal YM, Hanseman DJ, Gogela SL, Vuong SM, et al: Aneurysm growth and de novo aneurysms during aneurysm surveillance. J Neurosurg 125:1374-1382, 2016

31. Sprengers ME, van Rooij WJ, Sluzewski M, Rinkel GJ, Velthuis BK, de Kort GA, et al: MR angiography follow-up 5 years after coiling: frequency of new aneurysms and enlargement of untreated aneurysms. AJNR Am J Neuroradiol 30:303-307, 2009

32. Stewart LA, Clarke M, Rovers M, Riley RD, Simmonds M, Stewart G, et al: Preferred Reporting Items for Systematic Review and Meta-Analyses of individual participant data: the PRISMA-IPD Statement. JAMA 313:1657-1665, 2015

33. Tsutsumi K, Ueki K, Morita A, Usui M, Kirino T: Risk of aneurysm recurrence in patients with clipped cerebral aneurysms: results of long-term follow-up angiography. Stroke 32:1191-1194, 2001

34. van der Schaaf IC, Velthuis BK, Wermer MJH, Majoie C, Witkamp T, de Kort G, et al: New detected aneurysms on follow-up screening in patients with previously clipped intracranial aneurysms: comparison with DSA or CTA at the time of SAH. Stroke 36:1753-1758, 2005

35. Wang JY, Smith R, Ye X, Yang W, Caplan JM, Radvany MG, et al: serial imaging surveillance for patients with a history of intracranial aneurysm: risk of de novo aneurysm formation. Neurosurgery 77:32-43, 2015

36. Wermer MJH, van der Schaaf IC, Velthuis BK, Algra A, Buskens E, Rinkel GJE: Follow-up screening after subarachnoid haemorrhage: frequency and determinants of new aneurysms and enlargement of existing aneurysms. Brain 128:2421-2429, 2005
37. Wiebers DO, Whisnant JP, Huston J III, Meissner I, Brown RD Jr, Piepgras DG, et al: Unruptured intracranial aneurysms: natural history, clinical outcome, and risks of surgical and endovascular treatment. Lancet 362:103-110, 2003

38. Yoneoka Y, Takeda N, Akira I, Ibuchi Y, Kumagai T, Sugai T, et al: Ruptured de novo intracranial aneurysms. Acta Neurochir (Wien) 146:979-981, 2004

39. Zali A, Khoshnood RJ, Zarghi A: De novo aneurysms in long-term follow-up computed tomographic angiography of patients with clipped intracranial aneurysms. World Neurosurg 82:722-725, 2014

\section{Disclosures}

Dr. Lanzino reports that he is a consultant for Medtronic. Dr. Brinjikji is a consultant for Johnson and Johnson and is CEO of Marblehead Medical LLC.

\section{Author Contributions}

Conception and design: Lanzino, Giordan, Brinjikji. Acquisition of data: Giordan. Analysis and interpretation of data: Giordan. Drafting the article: Lanzino, Giordan, Brinjikji. Critically revising the article: Lanzino, Giordan, Murad, Brinjikji. Reviewed submitted version of manuscript: Lanzino, Giordan, Rangel-Castilla, Brinjikji. Approved the final version of the manuscript on behalf of all authors: Lanzino. Statistical analysis: Murad, Brinjikji. Administrative/technical/material support: Giordan. Study supervision: Lanzino, Giordan, Rangel-Castilla, Brinjikji.

\section{Correspondence}

Giuseppe Lanzino: Mayo Clinic, Rochester, MN. lanzino. giuspeppe@mayo.edu. 